\title{
STUDI PARAMETRIK PENGARUH POLA CURAH HUJAN terhadap JARAK JANGKAUAN (RUN-OUT) LONGSOR di LEMBANG-BANDUNG
}

\author{
Tia Miftahul Khoiriyah ${ }^{1, *)}$; Selly Feranie ${ }^{1}$; Adrin Tohari ${ }^{2}$ \\ ${ }^{1}$ Departemen Fisika FPMIPA, Universitas Pendidikan Indonesia, Jl. Dr. Setiabudhi No.229, Bandung, 40154 \\ ${ }^{2}$ Pusat Penelitian Geoteknologi LIPI, Komplek LIPI Jl. Sangkuriang Bandung \\ Email : *) tia.miftahul@gmail.com
}

\begin{abstract}
Abstrak
Longsor termasuk bencana alam yang sering terjadi di Jawa Barat. Banyak penelitian mengenai longsor. Salah satu penelitian didasarkan pada faktor penting pemicu terjadinya longsor yaitu pola curah hujan. Penelitian dilakukan di Lembang-Bandung sebagai daerah berpotensi longsor dengan menggunakan metode geologi teknik berupa uji karakteristik keteknikan tanah. Hasil dari karakterisasi keteknikan tanah berupa distribusi ukuran butir, porositas, permeabilitas, kohesi, dan dengan dilengkapi geometri lereng potensi longsor digunakan untuk mengidentifikasi besaran yang digunakan untuk mengetahui jarak jangkauan (run-out) longsor berdasarkan model gesekan Coloumb sederhana. Perubahan pola curah hujan yang dilakukan yaitu $0 \mathrm{~mm} / \mathrm{jam}, 0,1 \mathrm{~mm} / \mathrm{jam}, 5 \mathrm{~mm} / \mathrm{jam}, 10 \mathrm{~mm} / \mathrm{jam}, 20 \mathrm{~mm} / \mathrm{jam}$, dan 25 $\mathrm{mm} /$ jam menghasilkan stabilitas lereng (baca: faktor keamanan) yang berbeda-beda. Pola hujan ringan sedang menunjukan bahwa lereng berada dalam keadaan kritis dengan FK 1,001 sedangkan saat hujan lebat - sangat lebat menunjukan lereng berada dalam keadaan tidak stabil dengan $\mathrm{FK}<1$. Hal ini berpengaruh pada run-out longsor beserta kecepatan tanah. Semakin tinggi tingkat curah hujan maka lereng akan semakin tidak stabil sehingga tinggi awal pusat massa berubah menjadi lebih tinggi maka run-out longsor dan kecepatan pun semakin tinggi.
\end{abstract}

Kata-kata kunci: Pola Curah Hujan, Faktor Keamanan, Jarak Jangkauan (Run-Out)

\begin{abstract}
Landslide is one of the most frequent natural disasters in West Java. There is a lot of research conducted under landslides discussion. One of the researches was conducted based on one of the important factors that trigger landslides that is rainfall patterns. The research was conducted in Lembang, Bandung as it is an area potentially having landslide. The method used was geological method particularly using engineering characteristic such as the soil test. The results of engineering characterization of soil are in the form of grain size distribution, porosity, permeability, and cohesion. It is completed by potential landslide slope geometry in order to identify the unit used to determine the run-out of the landslide based on the friction model of simple Coulomb. Changes in rainfall patterns made is $0 \mathrm{~mm} / \mathrm{h}, 0.1 \mathrm{~mm} / \mathrm{h}$, $5 \mathrm{~mm} / \mathrm{h}, 10 \mathrm{~mm} / \mathrm{h}, 20 \mathrm{~mm} / \mathrm{h}$, and $25 \mathrm{~mm} / \mathrm{h}$ resulting different intensity of slope stability (read: safety factor). That are light-medium rainfall pattern then the value FK $\sim 1.001$, while heavy-torrential rainfall pattern then the value FK <1. It affects the run-out landslides including the ground speed. The higher of the rainfall level, the lower of the slope stability will be, It increases initial high center of mass and also resulting the higher of the run-out of landslides and it speed.
\end{abstract}

Keywords: Rainfall Patterns, Safety Factor, Run-Out 


\section{PENDAHULUAN}

Penelitian mengenai longsor telah dilakukan oleh banyak peneliti. Hal ini dikarenakan longsor termasuk peristiwa alam yang menimbulkan bencana dan kerugian material dengan intensitas cukup tinggi, terutama ketika musim penghujan. Menurut Cruden (1991) dalam [1], Longsor merupakan gerakan massa batuan, bahan rombakan, atau tanah yang menuruni lereng. Longsor disebabkan faktor utama berupa faktor alam, faktor manusia, dan kombinasi kedua faktor tersebut. Salah satu faktor alam yang menjadi penyebab terjadinya longsor adalah tingginya intensitas curah hujan [2]. Curah hujan mempengaruhi stabilitas lereng secara tidak langsung terhadap kondisi air-pori di dalam material pembentuk lereng [3]. Pada kondisi tanah dengan konduktivitas rendah akan terjadi infiltrasi dan rembasan air dengan volume lebih sedikit dibanding tanah dengan konduktivitas tinggi sehingga air tersebut akan mengalir kedalam tanah yang lebih dalam dan menyebabkan kenaikan muka air tanah [4]. Semakin deras hujan akan mengakibatkan air yang tertahan semakin meningkatkan debit dan volumenya, kapasitas infiltrasi tanah tersebut mencapai minimum karena sebagian besar pori terisi oleh air atau tanah berada dalam kondisi jenuh. Faktor keamanan lereng akan menurun seiring dengan lamanya infiltrasi air hujan yang terjadi di daerah tersebut [5].

Petrascheck dalam Rickenmann [6] menyatakan bahwa prediksi jarak jangkauan (run-out) bencana alam sangatlah penting untuk menentukan daerah yang terkena dan mengetahui intensitas parameter yang menjadi elemen penting dalam menghasilkan peta rawan bencana. Prediksi run-out longsor dapat diketahui dengan model Couloumb sederhana, seperti [7]. Besaran yang diperlukan dalam perhitungan prediksi run-out didapatkan dari hasil uji karakterisitik keteknikan tanah menggunakan metode geologi teknik.

Berdasarkan hal tersebut artikel ini menyajikan studi parametrik untuk mengetahui besaran runout longsor berdasarkan model gesekan Coloumb sederhana dengan variasi intensitas curah hujan.

\section{METODE PENELITIAN}

Penelitian ini dilakukan di Lembang-Bandung, $6,49^{\circ}$ LS dan $107,36^{\circ}$ BT yang merupakan daerah potensi longsor. Kegiatan pengambilan data yang dilakukan di lokasi longsor berupa pengukuran geometri serta pengambilan sampel tanah tak terganggu (undisturb) dan sampel tanah terganggu (disturb) untuk dilakukan karakterisasi melalui uji keteknikan tanah di Laboratorium. Informasi tersebut digunakan untuk memodelkan volume tanah yang tidak stabil dan kedalaman bidang gelincir, serta digunakan untuk simulasi numeris variasi pola curah hujan menggunakan Geo-Seep/W untuk kemudian dilakukan analisis stabilitas lereng menggunakan Geo-Slope/W. yang diperlukan untuk mengetahui prediksi run-out longsor model gesekan Couloumb sederhana. Adapun alur penelitian yang akan dilakukan sebagai berikut :

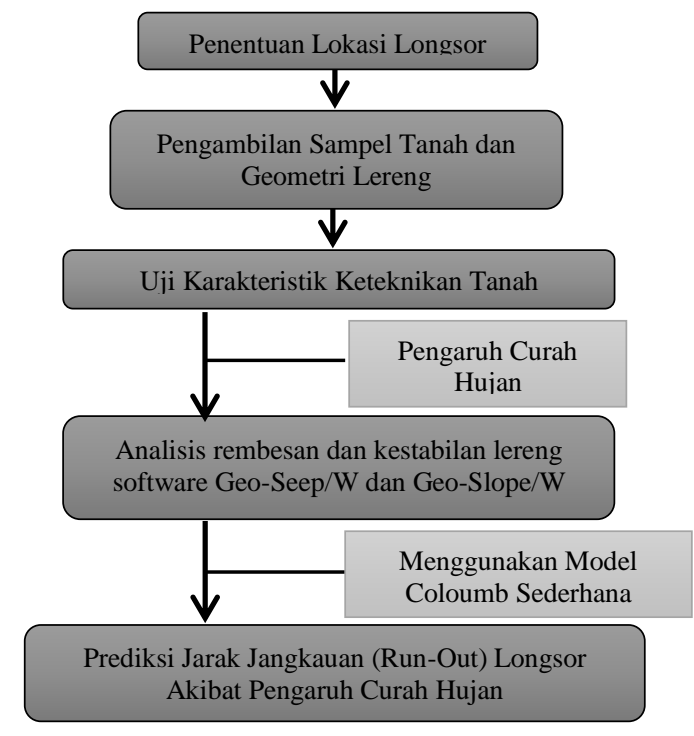

GAMBAR 1. Diagram Alur Penelitian 
Karakterisasi keteknikan tanah ini berupa uji standar ASTM D 2216 untuk menentukan kadar air (moisture content); uji standar ASTM D 7263 untuk menentukan berat isi, porositas dan derajat saturasi; uji standar ASTM D 5084 untuk menentukan koefisien rembesan/ hydraulic conductivity (k); uji standar ASTM D 422 untuk menganalisis ukuran butir (grain size analysis); uji standar ASTM D 854-00 untuk menentukan berat jenis (Specific Gravity); uji standar ASTM D-3080-04 untuk menentukan geser langsung (Direct Shear) tanah; uji standar ASTM D4318-84 untuk menentukan batas-batas Atterberg yaitu batas plastis (PL) dan batas cair (LL). Hasil karakterisasi tersebut dilengkapi geometri lereng kemudian digunakan untuk pemodelan.

Pemodelan dilakukan dengan mengubah nilai intensitas curah hujan yaitu $0 \mathrm{~mm} / \mathrm{jam}, 0,1 \mathrm{~mm} / \mathrm{jam}$, $5 \mathrm{~mm} / \mathrm{jam}, 10 \mathrm{~mm} / \mathrm{jam}, 20 \mathrm{~mm} / \mathrm{jam}$, dan $25 \mathrm{~mm} / \mathrm{jam}$ pada durasi yang sama. Hal ini berdasarkan TABEL 1. Kondisi batas (Boundary Condition) pada keadaan tersebut terjadi infiltrasi pada lereng dengan keberadaan muka air tanah yang konstan yaitu berada dibawah lereng.

Tabel 1. Intensitas Curah Hujan [8]

\begin{tabular}{lc}
\hline \multicolumn{2}{c}{ Intensitas Curah Hujan } \\
\hline Hujan Ringan & $0,1-5,0 \mathrm{~mm} / \mathrm{jam}$ \\
\hline Hujan Sedang & $5-10 \mathrm{~mm} / \mathrm{jam}$ \\
\hline Hujan Lebat & $10-20 \mathrm{~mm} / \mathrm{jam}$ \\
\hline Hujan Sangat Lebat & $>20 \mathrm{~mm} / \mathrm{jam}$ \\
\hline
\end{tabular}

Infiltrasi hujan akan mengurangi tekanan air pori negatif tanah mengakibatkan berkurangnya kuat geser tanah. Penurunan kekuatan geser tanah selanjutnya dapat menimbulkan ketidakstabilan lereng, [9]. Persamaan kuat geser pada kondisi tak jenuh berbeda dengan keadaan jenuh dengan hadirnya parameter tekanan air pori negatif (matric suction), sebagaimana berikut:

Dimana

$$
\tau=c^{\prime}+\left(\sigma-u_{a}\right) \tan \phi^{\prime}+\left(u_{a}-u_{w}\right) \tan \phi^{b}
$$

$\tau=$ tegangan geser $(\mathrm{kPa})$

$\mathrm{c}^{\prime}=$ kohesi efektif $(\mathrm{kPa})$

$\phi^{\prime}=$ sudut internal efektif $\left(^{\circ}\right)$

$u_{a}=$ tekanan udara $(\mathrm{kPa})$

$u_{a}=$ tekanan air pori $(\mathrm{kPa})$

$\left(u_{a}-u_{w}\right)=$ matric suction $(\mathrm{kPa})$

$\phi^{b}=$ sudut internal akibat adanya matric suction saat $\left(\sigma-u_{a}\right)$ konstan $\left(^{\circ}\right)$

Lereng yang stabil terjadi karena meningkatnya matric suction sehingga mengakibatkan meningkatnya tahanan geser tanah yang ditandai dengan membesarnya parameter c' dan $\phi^{\prime}$. Sebaliknya Ketidakstabilan lereng akan terjadi ketika terjadi penurunan matric suction akibat infiltrasi air hujan sehingga menyebabkan menurunnya kuat geser tanah.

Analisis stabilitas lereng berkaitan dengan faktor keamanan suatu lereng. Metode yang digunakan ialah Metode Morgenstern-Price. Metode ini dapat digunakan untuk semua bentuk bidang runtuh dan telah memenuhi semua kondisi kesetimbangan. Perhitungan faktor keamanan dilakukan dengan menggunakan kesetimbangan gaya dalam arah horisontal dan kesetimbangan momen pada pusat gelinciran untuk semua irisan, dan menggunakan kondisi kesetimbangan gaya dan momen dari setiap irisan [10].

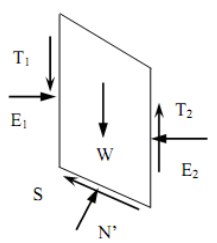

GAMBAR 2. Diagram gaya antar irisan dalam Metode Morgenstern-Price 
Dimana $\mathrm{W}=$ gaya berat, $\mathrm{S}=$ gaya gesek di dasar dalam arah horizontal (friction), $\mathrm{T}$ =gaya gesek dalam arah vertikal, $\mathrm{E}=$ gaya normal dalam arah horizontal, dan $\mathrm{N}=$ total gaya normal.

Prediksi run-out menggunakan model Coloumb sederhana didapatkan dengan menghitung energi potensial awal yang dimiliki oleh massa tanah yang tidak stabil. Massa tanah yang bergerak hanya dipengaruhi oleh gaya gravitasi dan gaya gesek bidang gelincir statis [11].

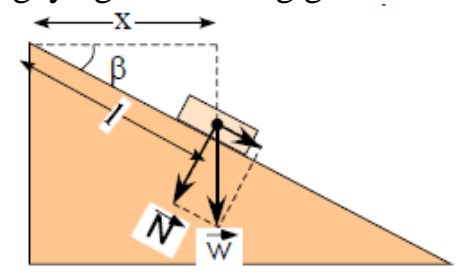

GAMBAR 3. Model gesekan Coloumb Sederhana [12]

Koefisien gesek didapatkan dari hubungan keseimbangan gaya ketika benda tepat akan bergerak, sebagai berikut :

$$
\begin{gathered}
F_{\text {benda }}=F_{\text {gesek }} \\
m g \sin (\beta)=\mu N \\
m g \sin (\beta)=\mu m g \phi \cos (\beta) \\
\mu=\tan (\beta) \equiv \tan (\phi)
\end{gathered}
$$

$\vec{W}=m g$ dengan $\mathrm{m}=$ massa tanah dan $\mathrm{g}=$ percepatan gravitasi, $\mathrm{N}=$ gaya normal, $\phi, \beta=$ sudut gesek semu, ${ }^{\mu}=$ koefisien gesek

Berdasarkan hukum kekekalan energi, pada posisi awal massa tanah membawa energi potensial sebesar $E_{P}=m g H_{G}$, kemudian diubah menjadi energi kinetik. Pada saat massa tanah bergerak terdapat energi yang hilang akibat gesekan, seperti persamaan berikut :

$$
\begin{gathered}
E_{\text {gesek }}=F_{\text {gesek }} l=\mu|N| l=\mu m g \cos (\phi) . l \\
E_{\text {gesek }}=m g x \tan (\phi)
\end{gathered}
$$

GAMBAR 4. Pergerakan pusat massa tanah [12]

Dimana $\mathrm{H}_{\mathrm{G}}=$ tinggi awal pusat massa, $x=$ jarak pusat massa setelah berpindah, $\mathrm{h}(x)=$ tinggi pusat massa pada jarak $x, \mathrm{~L}_{\mathrm{G}}=$ jangkauan maksimum.

Pusat massa yang bergerak pada posisi $x$ akan mengubah kecepatan untuk setiap posisi yang dapat diturunkan berdasarkan hukum kekekalan energi, sebagai berikut :

$$
\begin{gathered}
E M=E M^{\prime} \\
\frac{1}{2} m v(x)^{2}+m g x \tan (\phi)=m g\left(H_{G}-h_{x}\right) \\
v(x)^{2}=2 g\left(H_{G}-h_{x}-x \tan (\phi)\right) \\
v(x)=\sqrt{2 g \Delta h}
\end{gathered}
$$

Jarak jangkauan maksimum dapat diperoleh dengan substitusi $v\left(x_{\max }\right)=0$ pada persamaan (3),

$$
L_{G}=x_{\text {maks }}=\frac{\left(H_{G}-h\left(x_{\text {maks }}\right)\right)}{\tan (\phi)}
$$


Kondisi dimana tanah telah berada dipermukaan, substitusi $h\left(x_{\max }\right)=0$ pada persamaan (5) menjadi

$$
L=\frac{H}{\tan (\phi)}
$$

Persamaan 6 merupakan persamaan umum untuk memprediksi run-out longsor berdasarkan model diskrit dengan pendekatan pusat massa.

\section{HASIL DAN PEMBAHASAN}

Hasil uji karakteristik keteknikan tanah di Laboratorium didapatkan data seperti pada TABEL 1 dan GAMBAR 5. Data tersebut merupakan parameter yang diperlukan untuk analisis stabilitas lereng dan analisis rembesan air tanah.

TABEL 2. Parameter tanah untuk analisis stabilitas lereng dan analisis rembesan air tanah.

\begin{tabular}{|c|c|c|}
\hline \multirow[t]{2}{*}{ Karakteristik Keteknikan Tanah } & \multicolumn{2}{|c|}{ Lembang-Bandung } \\
\hline & Bidang Gelincir & Bahan Longsor \\
\hline Berat Isi Tanah Basah $(\mathrm{g} / \mathrm{cm} 3)$ & 1,3 & 1,13 \\
\hline Berat Isi Tanah Kering (g/cm3) & 0,90 & 0,59 \\
\hline Berat Jenis $(\mathrm{g} / \mathrm{cm} 3)$ & 2,59 & 2,02 \\
\hline Derajat Kejenuhan (\%) & 67,22 & 75,66 \\
\hline Kadar Air (\%) & 48,57 & 89,19 \\
\hline Porositas (\%) & 65,17 & 70,44 \\
\hline Batas Cair (\%) & 71,89 & 78,08 \\
\hline Batas Plastis (\%) & 36,24 & 38,75 \\
\hline Batas Susut (\%) & 20,05 & 22,95 \\
\hline Indeks Plastisitas (\%) & 35,65 & 39,33 \\
\hline Koefisien Rembesan (cm/s) & \multicolumn{2}{|c|}{$1,84 \mathrm{E}-03$} \\
\hline Kohesi (kPa) & 2,12 & 1,64 \\
\hline Sudut Geser $\left({ }^{\circ}\right)$ & 57,70 & 55,3 \\
\hline
\end{tabular}

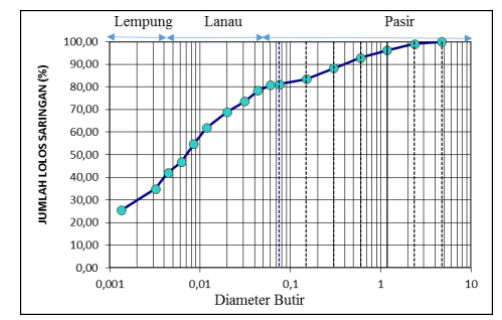

GAMBAR 5. Hasil uji distribusi ukuran butir

Setelah data tersebut diproses dengan pemodelan, maka didapatkan keadaan lereng yang berbedabeda tergantung parameter yang berubah. Keadaan lereng yang berbeda terjadi karena lereng atau tanah longsor tersebut terdiri dari material yang memiliki karakteristik berbeda. Hal tersebut terlihat tanah longsor bidang gelincir dan transisi memiliki Soil Water Characteristic Curve (SWCC) yang berbeda.

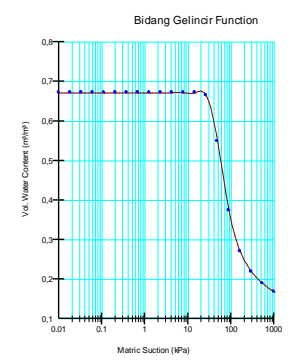

GAMBAR 6. Soil Water Characteristic Curve (SWCC) pada Bidang Gelincir

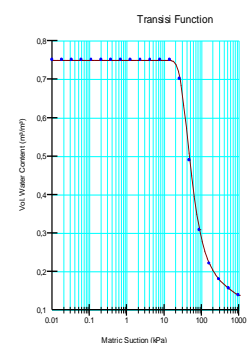

GAMBAR 7. Soil Water Characteristic Curve (SWCC) pada Transisi 
Berdasarkan Digram SWCC tersebut, hasil pemodelan keadaan lereng ketika terjadi infiltrasi air hujan sebagai berikut GAMBAR 8-12.

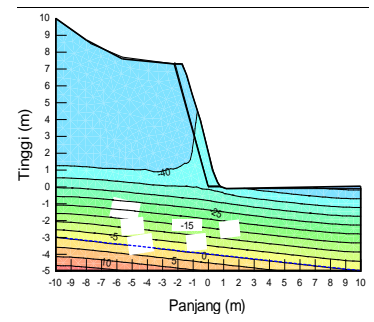

GAMBAR 8. Hasil analisis rembesan air tanah dengan intensitas curah hujan $0,1 \mathrm{~mm} / \mathrm{jam}$ dan durasi 6 jam.

GAMBAR 8-12 memperlihatkan bahwa intensitas curah hujan yang berbeda memberikan pengaruh terhadap kondisi lereng. Intensitas curah hujan yang tinggi akan menaikan muka air tanah seperti pada GAMBAR 11 dan GAMBAR 12 dan mengubah nilai tekanan air pori negatif menjadi tekanan air pori positif yang akan berdampak pada terganggunya stabilitas lereng.

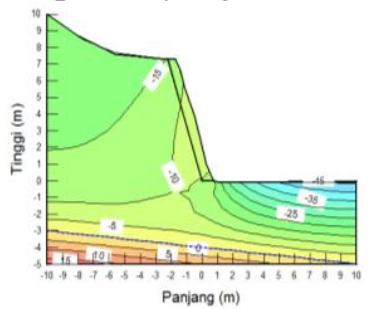

GAMBAR 9. Hasil analisis rembesan air tanah dengan intensitas curah hujan $5 \mathrm{~mm} / \mathrm{jam}$ dan durasi 6 jam

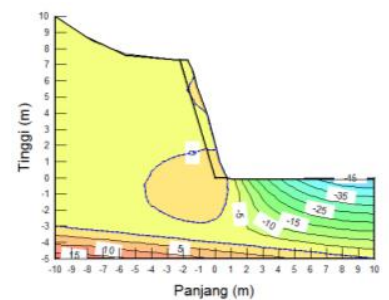

GAMBAR 11. Hasil analisis rembesan air tanah dengan intensitas curah hujan $20 \mathrm{~mm} / \mathrm{jam}$ dan durasi 6 jam

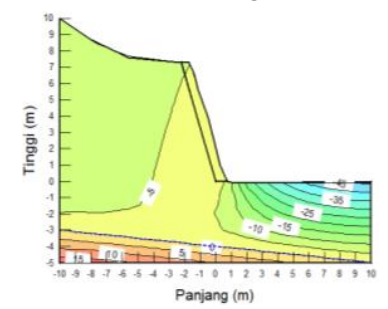

GAMBAR 10. Hasil analisis rembesan air tanah dengan intensitas curah hujan $10 \mathrm{~mm} / \mathrm{jam}$ dan durasi 6 jam

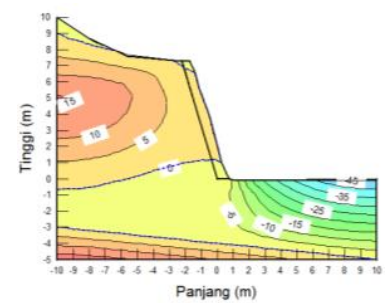

GAMBAR 12. Hasil analisis rembesan air tanah dengan intensitas curah hujan $25 \mathrm{~mm} / \mathrm{jam}$ dan durasi 6 jam

TABEL 2. Hasil analisis stabilitas lereng dengan pengubahan intensitas curah hujan

\begin{tabular}{cc}
\hline $\begin{array}{c}\text { Intensitas Curah Hujan } \\
(\mathbf{m m} / \mathbf{j a m})\end{array}$ & FK \\
\hline 0,1 & 1,001 \\
\hline 5 & 1,001 \\
\hline 10 & 1,001 \\
20 & 0,930 \\
25 & 0,882 \\
\hline
\end{tabular}

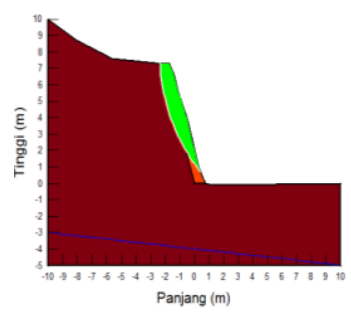

GAMBAR 13. Hasil analisis stabilitas lereng dengan intensitas curah hujan $0 \mathrm{~mm} / \mathrm{jam}, 0,1 \mathrm{~mm} / \mathrm{jam}, 5 \mathrm{~mm} / \mathrm{jam}$, dan $10 \mathrm{~mm} / \mathrm{jam}$

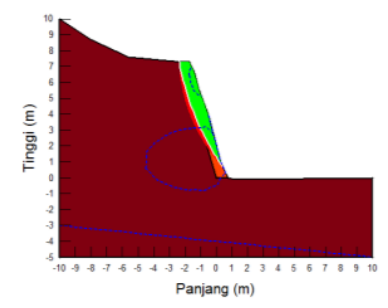

GAMBAR 14. Hasil analisis stabilitas lereng dengan intensitas curah hujan $20 \mathrm{~mm} / \mathrm{jam}$ 


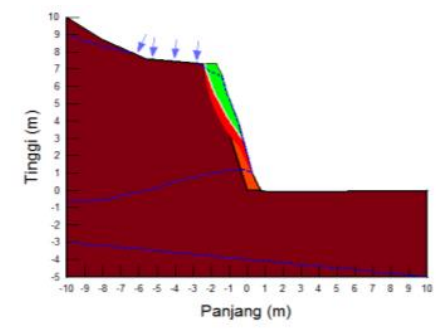

GAMBAR 15. Hasil analisis stabilitas lereng dengan intensitas curah hujan $25 \mathrm{~mm} / \mathrm{jam}$

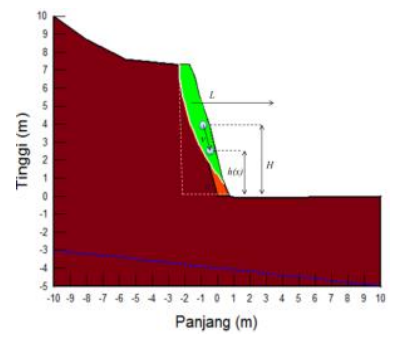

GAMBAR 16. Parameter geometri yang digunakan dalam perhitungan kecepatan dan run-out pusat massa tanah bahan longsoran.

Hasil analisis stabilitas lereng berupa FK didapatkan seperti pada Tabel 2. FK 1 menunjukan bahwa lereng tersebut dalam kondisi kritis. Pada saat terjadi hujan dengan intensitas $0,1 \mathrm{~mm} / \mathrm{jam}, 5$ $\mathrm{mm} / \mathrm{jam}$, dan $10 \mathrm{~mm} / \mathrm{jam}$ maka kondisi lereng masih berada dalam keadaan kritis hingga belum menimbulkan longsor. Sedangkan pada hujan lebat hingga hujan sangat lebat dengan intensitas 20 $\mathrm{mm} / \mathrm{jam}$ dan $25 \mathrm{~mm} / \mathrm{jam}$, intensitas curah hujan ini mengganggu stabilitas lereng yang diartikan dapat menimbulkan longsor. Hal ini sesuai dengan hasil analisis rembesan air tanah pada kondisi hujan tersebut menimbulkan lereng tersebut membentuk muka air tanah baru dan mengubah tekanan air pori keseluruhan massa tanah longsor menjadi positif. Prediksi run-out longsor dapat diketahui setelah mendapatkan nilai parameter yang diperlukan, salah satunya berdasarkan analisis stabilitas lereng.

TABEL 3. Hasil prediksi run-out longsor

\begin{tabular}{|l|c|c|c|c|c|c|}
\hline \multirow{2}{*}{ Parameter } & \multicolumn{5}{|c|}{ Intensitas Curah Hujan (mm/jam) } \\
\cline { 2 - 7 } & $\mathbf{0}$ & $\mathbf{0 , 1}$ & $\mathbf{5}$ & $\mathbf{1 0}$ & $\mathbf{2 0}$ & $\mathbf{2 5}$ \\
\hline $\begin{array}{l}\text { Tinggi awal } \\
\text { pusat massa } \\
(H), \mathrm{m}\end{array}$ & 3,5 & 3,5 & 3,5 & 3,5 & 4,5 & 5,5 \\
\hline $\begin{array}{l}\text { Tinggi saat } \\
\text { berada di jarak } \\
\mathrm{x} h(x), \mathrm{m}\end{array}$ & 2,5 & 2,5 & 2,5 & 2,5 & 2,5 & 2,5 \\
\hline $\begin{array}{l}\text { Sudut Geser } \\
(\phi)\end{array}$ & $73^{\circ}$ & $73^{\circ}$ & $73^{\circ}$ & $73^{\circ}$ & $73^{\circ}$ & $73^{\circ}$ \\
\hline $\begin{array}{l}\text { Koefisien } \\
\text { Gesek }(\mu)\end{array}$ & 3,27 & 3,27 & 3,27 & 3,27 & 3,27 & 3,27 \\
\hline $\begin{array}{l}\text { Jangkauan } \\
\text { pergerakan } \\
\text { pusat massa } \\
\text { tanah }(L), \mathrm{m}\end{array}$ & 1,07 & 1,07 & 1,07 & 1,07 & 1,38 & 1,76 \\
\hline $\begin{array}{l}\text { Kecepatan } \\
\mathrm{m} / \mathrm{s} \text { ( }\end{array}$ & 4,83 & 4,83 & 4,83 & 4,83 & 6,55 & 7,90 \\
\hline
\end{tabular}

TABEL 3 menunjukan bahwa intensitas curah hujan ringan dan sedang memiliki run-out longsor dan kecepatan yang sama yaitu $1,07 \mathrm{~m}$ dan $4,38 \mathrm{~m} / \mathrm{s}$. Hal ini dikarenakan hujan tidak mengubah tinggi awal pusat massa $(\mathrm{H})$. Telah diketahui bahwa tinggi awal pusat massa $(\mathrm{H})$ berubah menjadi lebih tinggi pada saat hujan lebat - sangat lebat $(20 \mathrm{~mm} / \mathrm{jam}$ dan $25 \mathrm{~mm} / \mathrm{jam})$. Hal ini berpengaruh pada run-out longsor menjadi lebih jauh yaitu $1,38 \mathrm{~m}$ dan $1,76 \mathrm{~m}$. Begitupun dengan kecepatan berubah lebih cepat menjadi $6,55 \mathrm{~m} / \mathrm{s}$ dan $7,90 \mathrm{~m} / \mathrm{s}$. Dengan run-out longsor seperti pada TABEL 3 diperkirakan massa tanah akan menutupi sebagian jalan. Serta kondisi lereng akan lebih berbahaya apabila hujan lebat karena menyebabkan tinggi awal pusat massa berubah menjadi lebih tinggi dengan run-out longsor lebih jauh dan kecepatan tanah longsor pun lebih cepat.

\section{KESIMPULAN}

Penelitian yang dilakukan di Lembang-Bandung, daerah berpotensi longsor dengan menggunakan metode geoteknik ini mengindikasikan bahwa perubahan pola curah hujan yaitu 0 
$\mathrm{mm} / \mathrm{jam}, 0,1 \mathrm{~mm} / \mathrm{jam}, 5 \mathrm{~mm} / \mathrm{jam}, 10 \mathrm{~mm} / \mathrm{jam}, 20 \mathrm{~mm} / \mathrm{jam}$, dan $25 \mathrm{~mm} / \mathrm{jam}$ menghasilkan stabilitas lereng yang berbeda-beda. Pola hujan ringan - sedang menunjukan bahwa lereng berada dalam keadaan kritis dengan FK 1,001 sedangkan saat hujan lebat - sangat lebat menunjukan lereng berada dalam keadaan tidak stabil dengan $\mathrm{FK}<1$. Hal ini berpengaruh pada run-out longsor beserta kecepatan tanah. Semakin tinggi tingkat curah hujan maka lereng akan semakin tidak stabil sehingga tinggi awal pusat massa berubah menjadi lebih tinggi maka run-out longsor dan kecepatan pun semakin tinggi.

\section{UCAPAN TERIMAKASIH}

Studi ini adalah bagian dari penelitian Hibah Bersaing yang didanai DIKTI tahun 2016 hasil kerjasama dengan Pusat Penelitian Geoteknologi LIPI Bandung.

\section{DAFTAR ACUAN}

[1] C.V. Westen. Introduce to landslide, part 1 : types and causes. International Institute for Aerospace Survey and earth Sciences (ITC), Enschede, The Netherlands.

[2] Purwanto. Tinjauan hidrogeologi dan evaluasi gerakan tanah di wilayah kabupaten banjarnegara. Prosiding Seminar Nasional Aplikasi Sains dan Teknologi (2008). - IST AKPRIND Yogyakarta.

[3] G. Sarya, A.H.Andriawan, A.Ridho'i, H. Saputro. Intensitas curah hujan memicu tanah longsor dangkal di Desa Wonodadi Kulon. Jurnal Pengabdian LPPM Untag Surabaya (2014), $1(1)$, p. $65-71$.

[4] N. Gofar, L.M. Lee, A. Kassim. Effect Of Surface Boundary Condition On Rainfall Infiltration. Jurnal Teknologi, 44(B) Jun (2006), p. 63-70. Universiti Teknologi Malaysia.

[5] P. Dewantanu, M. Taufik. Analisis Pengaruh Infiltrasi Air Hujan Terhadap Kestabilan Lereng Pada Kontruksi Timbunan Tanah. (2011). Teknik Sipil, Universitas Islam Sultan Agung Semarang.

[6] Rickenmann. Chapter 13 - run-out prediction methods. M.Jakob and O.Hungr (eds), Debrisflow Hazard and Related Phenomena. (2005). Springer Berlin Heidelberg.

[7] Firmansyah, S. Feranie, A. Tohari, F.D.E. Latief. Prediksi jangkauan pergerakan tanah longsor menggunakan model gesekan Coulomb sederhana. Prosiding Simposium Nasional Inovasi dan Pembelajaran Sains 2015 (SNIPS 2015).

[8] Badan Meteorologi Klimatologi dan Geofisika. Prakiraan Cuaca Mingguan. [online]. Diakses dari http://meteo.bmkg.go.id/prakiraan/mingguan, April 2016.

[9] A.J. Syahbana, A.Tohari, E. Soebowo, D. Sarah, K. Sugianti. Desain cut slope chart untuk evaluasi kestabilan lereng di atas badan jalan. Studi Kasus: Cinona, Cisalak dan Cijengkol, Kabupaten Bandung Barat , Jawa Barat. Jurnal Lingkungan dan Bencana Geologi, Vol. 4 No. 1 April 2013: 33 - 47. Pusat Penelitian Geoteknologi LIPI.

[10] A.H.V.D. Sianipar, I.Rudi. Alternatif Perkuatan Lereng Pada Ruas Jalan Medan - Berastagi, Desa Sugo Km 25+200. Departemen Teknik Sipil (2014), Universitas Sumatera Utara.

[11] M. Jaboyedoff dan V. Labiouse. Technical Note: Preliminary estimation of rockfall run-out zones, Natural Hazards and Earth System Sciences 2011, 11, p.819-828.

[12] M. Jaboyedoff, P. Horton, A. Loye, dan A. Pedrazzini. Run-out-empirical approaches. Workshop Barcelona 2008 Mountain Risks. 